\title{
Progression of Disease and Viral Agents in Infants Hospitalized for Lower Respiratory Tract Infections
}

\author{
(1) Ayşe Banu Esen1, (1) Meltem Erol2, (1) Didem Kafadar33, (1) Özlem Bostan Gayret2, (1) Özgül Yiğit2, \\ (D) Tuğçe Damla Dilek2, (1) Kübra Yılmaz² \\ 1'istanbul Bağcılar Training and Research Hospital, Clinic of Clinical Microbiology, İstanbul, Turkey \\ 2istanbul Bağcılar Training and Research Hospital, Clinic of Pediatrics, İstanbul, Turkey \\ 3̇stanbul Bağcılar Training and Research Hospital, Clinic of Family Medicine, İstanbul, Turkey
}

\begin{abstract}
Aim: Acute viral respiratory tract infection is the leading cause of hospitalization for infants and young children in developed countries and is a major cause of death in developing countries. The aim of this study was to identify the viruses in children hospitalized for lower respiratory tract infections (LRTI) during the winter period and to evaluate the relationship between the clinical features of these patients and the severity of their disease.

Materials and Methods: The nasopharyngeal aspirates of 200 patients aged 0-24 months hospitalized with a diagnosis of LRTI were analyzed using the real-time polymerase chain reaction method. We looked for associations between the viral agent, duration of hospitalization and respiratory distress scale.

Results: The viral factor was identified in 150 (75\%) patients. Rhinovirus was the most frequent viral agent followed by respiratory syncytial virus and adenovirus; (52.67\%), (16.0\%) and (8.67\%) respectively. The average length of hospitalization for respiratory syncytial virus $(p=0.001)$, adenovirus $(p=0.009)$, influenza A virus $(p=0.007)$, and bocavirus $(p=0.009)$ infections were significantly longer. Adenovirus $(p=0.029)$, respiratory syncytial virus $(p=0.001)$ and bocavirus $(p=0.009)$ were significantly associated with length of hospitalization. No significant correlation was identified between the viruses and respiratory distress scores ( $p>0.05)$.

Conclusion: We conclude that in hospitalized children with LRTIs, rhinovirus was the most frequently observed viral etiological agent. A longer period of hospitalization was needed for respiratory syncytial virus, adenovirus and bocavirus in infants with LRTIs. Infants with respiratory infections should be monitored due to the risk of developing severe complications during disease progression.
\end{abstract}

Keywords: Infant, rhinovirus, respiratory syncytial virus, adenovirus, respiratory tract infections, hospitalization

\section{Introduction}

Lower respiratory tract infections (LRTI) are the most common cause of mortality and morbidity among children around the world (1). Acute respiratory tract infection is one of the main reasons for the hospitalization in the young age group, especially in developing countries. Respiratory viruses play a significant role in LRTI in children under the age of one year $(2,3)$. Most viruses spread via droplets and cause infection primarily in the epithelium of the respiratory tract. Simple RTI such as bronchiolitis may cause respiratory failure, especially in children, by initiating severe diseases such as chronic respiratory disorders, and triggering acute asthma attacks (4). Adenovirus, 
coronavirus, and rhinovirus cause endemic infections whereas influenza, parainfluenza virus (PIV), and respiratory syncytial virus (RSV) generally cause epidemics. In addition to the known factors, many studies have been conducted on viral factors and epidemiological information to identify the next generation of respiratory viruses such as human metapneumovirus, coronavirus and bocavirus, which have caused acute respiratory failure recently (5). LRTIs related to viruses create a significant load even in developed countries. Nevertheless, mortality and morbidity are significantly higher in developing countries than developed countries (6). Clinical findings and epidemiological features may vary in different geographical areas (7). In Turkey, there have been only a limited number of studies concerning viral etiology in LRTI. In this study, we aimed to identify the viruses in children hospitalized with LRTI during the winter period and to evaluate the relationship between the clinical features of these patients and the severity of the disease.

\section{Material and methods}

This single-center, prospective study was conducted at the Department of Pediatrics at a general tertiary referral state hospital. The hospital is located is one of the most populated regions of a metropolitan city.

The study protocol was approved by the Research Ethics Committee of Bağcılar Training and Research Hospital (approval number: 2015-425) in accordance with the Declaration of Helsinki. Informed consent was obtained from the parents of all study participants.

\section{Study Population}

Children aged 0-24 months who were diagnosed with LRTI and were hospitalized at the department of pediatrics, which contains 40 beds, were eligible for inclusion in our study population. The diagnosis of LRTI was made with regard to the complaints of coughing, fever, and respiratory distress, along with clinical findings such as slight rales and rhonchus, and infiltration findings on the chest radiography.

Those children who had an infection along with LRTI, metabolic or endocrine disease, chronic lung disease, heart disease, growth retardation or a history of premature birth and whose families refused to give informed consent were excluded from the study.

There were 300 patients aged 0-24 months who were hospitalized in the department of pediatrics due to LTRI in the period between November 2015 and April 2016. The families of 23 patients refused to participate in the study, 27 patients did not meet the inclusion criteria and the samples of 50 patients were spoiled during the process, so 200 out of 300 participants (aged between 0 and 2 years) were included in the study.

\section{Lower Respiratory Tract Infections}

Both pneumonia and acute viral bronchiolitis are major causes of LRTIs in children. In the literature, there is evidence from a number of studies that the infectious base of both acute pneumonia and acute bronchiolitis in children has a mixed etiology of microorganisms (8). A diagnosis of an LRTI should be considered in any child who has an acute onset of respiratory symptoms, particularly cough, fast breathing or difficulty in breathing. Diagnosis includes clinical evaluation, radiographic evaluation and etiological investigations to distinguish between pneumonia and bronchiolitis. The management of the severity of the disease is based on the determination of the causative organisms where possible and necessary. Chest radiographs are taken in all of these patients to confirm the presence of pneumonia and detect complications such as a lung abscess or empyema.

\section{Severity of the Disease}

The severity of the disease was evaluated using the respiratory distress scale designed by Bezerra et al. (9) and the patients were evaluated as very mild, mild, moderate, or severe according to the scores of the scale.

Disease severity was assessed at the time of enrolment and categorized as follows:

1. Very mild (upper respiratory tract symptoms/signs only): Upper respiratory tract symptoms are coryza, aching ear, a sore throat and stridor.

2. Mild (lower respiratory tract symptoms/signs $+/ 2$ upper respiratory tract symptoms/signs but not needing hospital admission).

3. Moderate (lower respiratory tract symptoms/signs +/2 upper respiratory tract symptoms/signs, needing hospital admission but with oxygen saturations in air 93\% on pulse oximetry).

4. Severe (lower respiratory tract symptoms/signs $+/ 2$ upper respiratory tract symptoms/signs, needing hospital admission and oxygen with saturations in air 93\%).

Lower tract symptoms were classified by the presence of fever, tachypnoea, rhonchi with a respiratory rate as per minute, wheezing, focal or diffuse crackles or decreased vesicular sounds on auscultation and retraction at the end of expiration. Pneumonia was diagnosed according to both clinical or radiologic manifestations in the patient. Cyanosis, dehydration, severe respiratory distress and apnea were diagnosed as severe disease $(9,10)$. 
Patients who were in the very mild stage were not hospitalized, mild patients were hospitalized only if they were under 3 months old, moderate and severe patients were hospitalized.

\section{Sample Collection}

The nasopharyngeal swab samples of the patients were collected with Vircell branded swabs. The swabs were kept in an appropriate transport medium (HEPES, gelatin, bovine serum albumin, sucrose, and Hank's balanced salt solution including coherent antibiotics) at $-80{ }^{\circ} \mathrm{C}$ until the study was conducted. The samples were transferred to the lontech Microbiology Laboratory in accordance with cold chain regulations.

\section{Laboratory Measurements}

The RNA/DNA isolation, the reverse transcription of RNA, and Real-time amplification were applied to the samples using the ARVI Screen Real-Time-polymerase chain reaction (PCR) kit (Sacace Biotechnologies S.r.I, Italy).

The RNA samples obtained were studied using a commercial kit (Sacace, ARVI Screen real-TM, hRSV Real-TM, Influenza A, B Real-TM). The cDNA synthesis was performed using a component (Reverta-L) of the kit.

\section{Real-time Polymerase Chain Reaction Analyses}

The cDNAs obtained were studied in a Rotor-gene brand (Qiagen) Real-Time-PCR device. Human PIV-1-4 RNA, HKUI human coronavirus RNA, human rhinovirus RNA, human $B, C$, and $E$ adenovirus DNA, human bocavirus (hBov) DNA and Influenza A, B and hRSV were studied using commercial RT-PCR kits. Positive and negative controls were included in the RT-PCR analysis.

\section{Statistical Analysis}

SPSS ver. 23 (IBM Corp. Armonk, NY, USA) statistical package was used for the statistical evaluation. Descriptive statistics are indicated as frequencies and percentages for categorical variables and as means \pm standard deviation for continuous variables. In the comparison of the categorical variables, the chi-square test or Fisher's exact probability test were used conditionally. Normal distribution was tested with the Kolmogorov-Smirnov test for continuous variables, while the two-independent-samples t-test was used in the comparison of continuous variables consistent with a normal distribution of two independent groups. Median and Interquartile Range (IQR) values were used for non-normal distributions. The post-hoc power analysis test was used for statistically significant results. MannWhitney $U$ test, Kruskal-Wallis tests were used where appropriate. Logistic regression analysis was performed. A $p$ value less than 0.05 was accepted as indicating statistical significance.

\section{Results}

A total of 200 patients who were hospitalized with a diagnosis of LRTI and who were eligible according to the criteria mentioned before were included in this study. Viral agents were identified in 150 (75\%) of these 200 patients by PCR analyses.

Among these 150 patients, 79 were male (52.67\%) and 71 were female $(47.33 \%)$, and the mean patient age was $7.33 \pm 4.72$ months.

In 139 patients, only one viral agent was identified. The distribution of the viruses among virus detected subjects was as follows: Rhinovirus in 79 patients (52.67\%), RSV in 24 patients (16.0\%), adenovirus in 13 patients (8.67\%), influenza B virus in 7 patients $(4.67 \%)$, bocavirus in 6 patients $(4.0 \%)$, coronavirus in 5 patients $(3.33 \%)$, and influenza A virus in 5 patients (3.33\%).

Moreover, it was observed that certain viruses co-existed in $11(7.33 \%)$ patients. Rhinovirus and RSV co-existed in 8 of these patients, RSV and bocavirus co-existed in 2 patients, and RSV and influenza A virus co-existed in 1 patient. No PIV was detected in any of the patients.

Blood cultures were performed for all patients, the cultures remained negative for any bacterial agents.

The patients presented mostly with coughing as the initial symptom and this was followed by wheezing, high fever, and respiratory distress. The clinical findings of the patients were evaluated by the respiratory distress scale described by Bezerra et al. (9). We observed that 55 patients were mildly distressed, 69 patients were moderately distressed, and 26 patients were severely distressed.

Table I. Relationship between Respiratory Tract Viruses and Respiratory Distress score

There were no differences between the respiratory distress scores of patients when compared in terms of the presence of the various respiratory tract virus (Table I).

Table II. Relationship between Respiratory Tract Viruses and the Length of Hospitalization

The mean duration of hospitalization of the patients was $3.72 \pm 3.06$ days. When the relationship between the presence of viruses causing LRTI and the duration of hospitalization was evaluated, it was observed that the mean length of hospitalization for patients infected with RSV, adenovirus, influenza A and bocavirus was significantly 
longer $(p=0.001, p=0.009, p=0.007, p=0.009)$ respectively (Table II).

\section{Table III. Logistic Regression Analysis of Viral Etiology Associated with Length of Hospitalization}

To determine the factors that affected the duration of hospitalization most, logistic regression analysis was performed using viral factors as variables. Adenovirus $(p=0.029)$, RSV ( $p=0.001)$ and Bocavirus $(p=0.009)$ were significantly associated with length of hospitalization (Table III).

Patients with co-existing viruses endured longer hospital stays and 2 patients with rhinovirus and RSV and 1 patient with RSV and bocavirus were monitored in the intensive care unit.

\section{Discussion}

We identified viral agents in 150 (75\%) hospitalized children with LRTI aged 0-2 years. The rate was found to be between $35-90 \%$ in studies conducted previously on hospitalized children (11-15). These viruses cause mild to severe disease LRTI. In our study, for those patients in which infections progressed severely, RSV, adenovirus, bocavirus and coronavirus were identified as the viral agents (Table I).

\begin{tabular}{|c|c|c|c|c|c|c|}
\hline \multirow{2}{*}{\multicolumn{2}{|c|}{$\begin{array}{l}\text { Respiratory viruses } \\
\text { Mild }\end{array}$}} & \multicolumn{3}{|l|}{ Scoring } & \multirow{3}{*}{$\begin{array}{l}\text { Total, } \mathbf{n}=\mathbf{1 5 0} \\
79\end{array}$} & \multirow{2}{*}{$p$ value } \\
\hline & & \multirow{2}{*}{\begin{tabular}{|l|} 
Moderate \\
26 \\
\end{tabular}} & \multirow{2}{*}{\begin{tabular}{|l} 
Severe \\
38
\end{tabular}} & \multirow[b]{2}{*}{15} & & \\
\hline \multirow{4}{*}{ Rhinovirus } & $(+) n$ & & & & & \multirow[t]{2}{*}{0.587} \\
\hline & $\%$ & $31.0 \%$ & $50.7 \%$ & $18.3 \%$ & $100.0 \%$ & \\
\hline & $(-) n$ & 29 & 31 & $\mid 11$ & 71 & \\
\hline & $\%$ & $40.8 \%$ & $43.7 \%$ & 15.5\% & $100.0 \%$ & \\
\hline \multirow{4}{*}{$\begin{array}{l}\text { Respiratory syncytial } \\
\text { virus }\end{array}$} & $(+) n$ & 6 & 11 & 7 & 24 & \multirow{2}{*}{0.186} \\
\hline & $\%$ & $25.0 \%$ & $45.8 \%$ & $29.2 \%$ & $100.0 \%$ & \\
\hline & $(-) n$ & 49 & 58 & 19 & 126 & \\
\hline & $\%$ & $38.9 \%$ & $46.0 \%$ & 15.1\% & $100.0 \%$ & \\
\hline \multirow{4}{*}{ Adenovirus } & $(+) n$ & 3 & 5 & 5 & 13 & \multirow{2}{*}{0.102} \\
\hline & $\%$ & $23.1 \%$ & $38.5 \%$ & $38.5 \%$ & $100.0 \%$ & \\
\hline & $(-) n$ & 52 & 64 & 21 & 137 & \\
\hline & $\%$ & $38 \%$ & $46.7 \%$ & 15.3\% & $100.0 \%$ & \\
\hline \multirow{4}{*}{ Influenza B } & $(+) n$ & 4 & 2 & 1 & 7 & \multirow{2}{*}{0.506} \\
\hline & $\%$ & $57.1 \%$ & $28.6 \%$ & $14.3 \%$ & $100.0 \%$ & \\
\hline & $(-) n$ & 51 & 67 & 25 & 143 & \\
\hline & $\%$ & $35.7 \%$ & $46.9 \%$ & | 17.5\% & $100.0 \%$ & \\
\hline \multirow{4}{*}{ Bocavirus } & $(+) n$ & 2 & 1 & 3 & 6 & \multirow{2}{*}{0.08} \\
\hline & $\%$ & $33.3 \%$ & $16.7 \%$ & $50.0 \%$ & $100.0 \%$ & \\
\hline & $(-) n$ & 53 & 68 & 23 & 144 & \\
\hline & $\%$ & $36.8 \%$ & $47.2 \%$ & $16 \%$ & $100.0 \%$ & \\
\hline \multirow{4}{*}{ Coronavirus } & $(+) n$ & 1 & 2 & 2 & 5 & \multirow{2}{*}{0.374} \\
\hline & $\%$ & $20 \%$ & $40 \%$ & $40 \%$ & $100.0 \%$ & \\
\hline & $(-) n$ & 54 & 67 & 24 & 145 & \\
\hline & $\%$ & $37.2 \%$ & $46.2 \%$ & $16.6 \%$ & $100.0 \%$ & \\
\hline \multirow{4}{*}{ Influenza A } & $(+) n$ & 0 & 4 & 1 & 5 & \multirow{2}{*}{0.200} \\
\hline & $\%$ & $0 \%$ & $80 \%$ & $20 \%$ & $100.0 \%$ & \\
\hline & $(-) n$ & 55 & 65 & 25 & 145 & \\
\hline & $\%$ & $37.9 \%$ & $44.8 \%$ & $\mid 17.2 \%$ & $100.0 \%$ & \\
\hline
\end{tabular}


Similar to other studies, (14-18) the severity of disease increased in patients infected with RSV. Bicer et al. (15) found that pneumonia comorbidity was $43.5 \%$ in hospitalized infants infiltrated with RSV. In our study, pneumonia comorbidity with infiltration on chest radiography was
$32.3 \%$ in children infected with RSV. RSV can be observed during the period from November to July and it reaches its peak during December to May (15).

Adenoviruses are generally observed during the period February to July, reaching a peak during the period April to

Table II. Relationship between respiratory tract viruses and the length of hospitalization

\begin{tabular}{|c|c|c|c|c|c|}
\hline Respiratory tract virus & $\begin{array}{l}\text { Length of hospitalization } \\
\text { (days) }\end{array}$ & p value & $\begin{array}{l}\text { Post-hoc } \\
\text { power }\end{array}$ & Median & IQR \\
\hline \multicolumn{6}{|l|}{ Rhinovirus } \\
\hline$(+)$ & $3.68 \pm 2.84$ & \multirow{2}{*}{0.879} & - & 3 & 2 \\
\hline$(-)$ & $3.76 \pm 3.31$ & & - & 3 & 3 \\
\hline \multicolumn{6}{|l|}{ RSV } \\
\hline$(+)$ & $6.4 \pm 4.28$ & \multirow{2}{*}{0.001} & $\% 99$ & 5 & 4 \\
\hline$(-)$ & $3.28 \pm 2.52$ & & - & 3 & 1 \\
\hline \multicolumn{6}{|l|}{ Adenovirus } \\
\hline$(+)$ & $5.69 \pm 3.8$ & \multirow{2}{*}{0.009} & $\% 69.47$ & 4 & 6 \\
\hline$(-)$ & $3.53 \pm 2.93$ & & & 3 & 2 \\
\hline \multicolumn{6}{|l|}{ Influenza B } \\
\hline$(+)$ & $3.00 \pm 2.38$ & \multirow{2}{*}{0.448} & - & 3 & 2 \\
\hline$(-)$ & $3.76 \pm 3.10$ & & - & 3 & 2 \\
\hline \multicolumn{6}{|l|}{ Bocavirus } \\
\hline$(+)$ & $7.67 \pm 4.45$ & \multirow{2}{*}{0.009} & $\% 69.2$ & 7 & 7 \\
\hline$(-)$ & $3.56 \pm 2.90$ & & - & 3 & 2 \\
\hline \multicolumn{6}{|l|}{ Coronavirus } \\
\hline$(+)$ & $4.60 \pm 2.70$ & \multirow{2}{*}{0.254} & - & 3 & 5 \\
\hline$(-)$ & $3.69 \pm 3.08$ & & - & 3 & 2 \\
\hline \multicolumn{6}{|l|}{ Influenza A } \\
\hline$(+)$ & $6.30 \pm 2.70$ & \multirow{2}{*}{0.007} & $\% 63.7$ & 7 & 5 \\
\hline$(-)$ & $3.62 \pm 3.04$ & & - & 3 & 2 \\
\hline
\end{tabular}

RSV: Respiratory syncytial virus, IQR: Interquartile range, Post-hoc power analysis test was used for statistically significant results

Table III. Logistic regression analysis of viral etiology associated with length of hospitalization

\begin{tabular}{|l|l|l|l|l|l|l|}
\hline \multirow{2}{*}{ Viral Agents } & B & SE & P & OR & \multicolumn{2}{|c|}{ OR 95\% CI } \\
\cline { 5 - 8 } & & & & Lower & Upper \\
\hline Rhinovirus & -0.008 & 0.053 & 0.878 & 0.992 & 0.893 & 1.101 \\
\hline RSV & 0.225 & 0.069 & $\mathbf{0 . 0 0 1}$ & 1.253 & 1.094 & 1.435 \\
\hline Adenovirus & 0.146 & 0.067 & $\mathbf{0 . 0 2 9}$ & 1.157 & 1.015 & 1.319 \\
\hline Influenza B & -0.124 & 0.197 & 0.527 & 0.883 & 0.601 & 1.298 \\
\hline Bocavirus & 0.205 & 0.078 & $\mathbf{0 . 0 0 9}$ & 1.228 & 1.053 & 1.431 \\
\hline Coronavirus & 0.071 & 0.111 & 0.52 & 1.074 & 0.864 & 1.335 \\
\hline Influenza A & 0.162 & 0.085 & 0.058 & 1.175 & 0.995 & 1.389 \\
\hline
\end{tabular}

OR: Odds ratio, Cl: Confidence interval, RSV: Respiratory syncytial virus, SE: Standard error 
June and they are reported to progress to severe and fatal (19). In our study, in adenovirus infections, the occurrence of fever and lung infiltration were significantly higher. In our study, adenoviruses had the third highest frequency (9.35\%) which is higher than previously reported in other studies conducted in Turkey in hospitalized children, namely $5.6 \%$ and $4.8 \%(12,15)$. Bezerra et al. (9) also found that adenoviruses were the second most frequent agents in hospitalized patients.

Coronaviruses rarely cause infection during the winter and spring months. In our study, this rate was determined to be $3.59 \%$, which is consistent with other studies. The coronavirus rate was reported as $7.6 \%$ by Prill et al. (20) and $1.6 \%$ by Lau et al. (21) in hospitalized children between the ages of 6 months and 5 years. It was determined to be $2.9 \%$ in another study conducted in Turkey (22).

We observed the ratio of bocavirus to be $4 \%$ in our study. In recent years, bocavirus was determined to be between $3 \%$ and $21.5 \%$, varying according to the region, in children with acute LRTI (23-25). When we observed the viral agents which caused the longest length of hospitalization RSV, adenovirus and bocavirus were prominent. In a local study, it was found that rhinoviruses were responsible for the longest lengths of hospitalization, after RSV (15). However, in our study, rhinoviruses had less effect on the length of hospitalization. RSV was the second virus to cause long-term hospitalization. For adenovirus, the length of hospitalization was significantly longer and also the respiratory distress score in patients infected with adenovirus varied from moderate to severe. The course of LRTI caused by adenoviruses includes a high and prolonged fever which may cause long hospitalization (19).

Bocavirus caused the longest length of hospitalization, namely $7.67 \pm 4.45$ days. Moreover, the respiratory distress scores of children infected with bocavirus was severe with infiltration on chest radiography, which is similar to previous studies $(26,27)$. Before the detection method of hBov was developed, children with LRTI were accepted as RSV-negative severe pneumonia patients $(28,29)$. We think that bocavirus infections may be responsible for these cases.

We found rhinovirus to be the most frequent virus (56.83\%) followed by RSV (17.26\%) and adenoviruses (9.35\%). In some studies, the most frequent bronchiolitis agent was observed to be RSV at a rate of $12-60 \%$ in hospitalized children under 2 years of age (14-18). In other studies, RSV and rhinovirus were both identified at high rates using the PCR method; $43.6 \%$ and $31.8 \%$, respectively, in children admitted to hospital with an acute respiratory infection (30). In a recent study conducted in Thailand, the most common respiratory viruses in hospitalized children with severe pneumonia were determined to be RSV, rhinovirus and adenovirus especially in infants (31).

In the literature, rhinoviruses were found to be responsible for LRTIs and were observed in $14-24 \%$ of children hospitalized with bronchiolitis $(4,32-35)$. In the study conducted by Beka et al. (32), the rate of rhinovirus in hospitalized infants under the age of 2 years was $43.7 \%$, while Xie et al. (36) reported $36.2 \%$ in children under the age of 1 year. It has been reported that rhinoviruses cause LRTI and bronchiolitis especially in children under 3 years of age $(37,38)$. Rhinoviruses were observed frequently in our study which was performed between November and April, which is the period when rhinoviruses were observed most often as reported by previous studies. The hospitalization in children with LRTI caused by rhinoviruses in infants during the spring and summer months and especially during March and April are reported to be more frequent $(34,39)$. We believe that the number of RSV cases in our study was limited since it was conducted over a period of 6 months.

Although rhinovirus is the most frequent virus we detected, we observed that the respiratory distress score was moderate in $50 \%$, mild in $31 \%$ and severe in $18.3 \%$ of children infected with rhinovirus. Mild or moderately severe LRTIs caused by rhinovirus were reported in studies $(12,14)$. Also, in the study conducted by Bicer et al. (15) bronchiolitis symptoms related to rhinoviruses were moderate to severe in $29.2 \%$ of children.

The rate of bronchiolitis due to influenza $A$ and $B$ was $0.8-12.8 \%$ in previous studies and we found the frequency of Influenza A and B to be $4.67 \%$ and $3.33 \%$ respectively $(14,15,18)$. Influenza A progressed moderately with fever and infiltration in the lungs and caused a long length of hospitalization at $6.30 \pm 2.3$ days.

We identified multiple factors in 11 samples (7.33\%). RSV was the most frequent co-infective virus particularly with rhinoviruses. In one study, $35 \%$ of children in the intensive care unit had multiple infections and RSV was the most frequent virus in mixed infections (24.3\%) (40). In our study, in the intensive care unit, RSV and rhinovirus co-existed in two out of three patients with severe symptoms and in one patient RSV and bocavirus co-existed. In another study, in $13.8 \%$ of children with LRTI, RSV, rhinovirus and hBov were the most frequent and multiple infections were identified similar to our study (41). However, the present viruses may 
we detected in the respiratory tract as pathogens, other viruses may be completely asymptomatic in children even if they are present.

One of the strengths of our study is that there are a limited number of studies in our country on the identification of viruses by rapid screening methods in children under the age of 2 years hospitalized with LRTI and this study adds novel information. However, our samples were obtained over a specific time frame, between November and April, not throughout the year and this is the limitation of our study.

\section{Conclusion}

In our study, rhinovirus was detected as the most common viral factor in 0-2 years old children who were hospitalized in late winter and early spring due to LRTI, which is different from the common study findings. Rhinovirus was followed by RSV and adenovirus. It appears that RSV and adenovirus play a role in the severity of the disease.

We suggest that infants with respiratory infections should be monitored for the risk of developing severe complications. We think this study will add information to the understanding of viral LRTIs of the infancy period.

\section{Acknowledgements}

The study was supported by the Hospital Educational and Planning Committee and laboratory equipment was funded by the hospital.

\section{Ethics}

Ethics Committee Approval: The study protocol was approved by the Research Ethics Committee of Bağcılar Training and Research Hospital (approval number: 2015-425) in accordance with the Declaration of Helsinki.

Informed Consent: Informed consent was obtained from the parents of all study participants.

Peer-review: Externally and internally peer-reviewed.

\section{Authorship Contributions}

Surgical and Medical Practices: A.B.E., M.E., Ö.B.G., Ö.Y., Concept: A.B.E., M.E., Ö.B.G., Design: A.B.E., M.E., Data Collection or Processing: T.D.D., K.Y., Ö.B.G., Analysis or Interpretation: D.K., Ö.B.G., Ö.Y., Literature Search: D.K., T.D.D., K.Y., Ö.Y., Writing: M.E., D.K., A.B.E.

Conflict of Interest: The authors have no conflicts of interest relevant to this article to disclose.

Financial Disclosure: The authors have no financial relationships relevant to this article to disclose.

\section{References}

1. Souza PG, Cardoso AM, Sant'Anna CC, March MFBP. Acute lower respiratory infection in Guarani indigenous children, Brazil. Rev Paul Pediatr 2018;36:123-31.

2. Nayani K, Naeem R, Munir O, et al. The clinical respiratory score predicts paediatric critical care disposition in children with respiratory distress presenting to the emergency department. BMC Pediatr 2018;18:339.

3. Lozano R, Naghavi M, Foreman K, et al. Global and regional mortality from 235 causes of death for 20 age groups in 1990 and 2010: a systematic analysis for the Global Burden of Disease Study 2010. Lancet 2012;380: 2095-128.

4. Papadopoulos NG, Christodoulou I, Rohde G, et al. Viruses and bacteria in acute asthma exacerbations--a GA ${ }^{2}$ LEN-DARE systematic review. Allergy 2011;66:458-68.

5. Fernandes-Matano L, Monroy-Muñoz IE, Angeles-Martínez I, et al. Prevalence of non-influenza respiratory viruses in acute respiratory infection cases in Mexico. PLoS One 2017;12:e0176298

6. Nair $H$, Nokes D), Gessner BD, et al. Global burden of acute lower respiratory infections due to respiratory syncytial virus in young children: a systematic review and meta-analysis. Lancet 2010;375:1545-55

7. Choi EH, Lee HJ, Kim SJ, et al. The association of newly identified respiratory viruses with lower respiratory tract infections in Korean children, 2000-2005. Clin Infect Dis 2006;43:585-92.

8. World Health Organization. Revised WHO classification and treatment of childhood pneumonia at health facilities. World Health Organization. 2014.

9. Bezerra PG, Britto MC, Correia JB, et al. Viral and Atypical Bacterial Detection in Acute Respiratory Infection in Children Under Five Years. PLoS One 2011;6:e18928

10. Virkki $R$, Juven $T$, Rikalainen $H$, Svedström E, Mertsola J, Ruuskanen O. Differentiation of bacterial and viral pneumonia in children. Thorax 2002;57:438-41.

11. Sung R, Chan P, Tsen T, et al. Identification of viral and atypical bacterial pathogens in children hospitalized with acute respiratory infections in Hong Kong by multiplex PCR assays. I Med Virol 2009;81:153-9.

12. Hatipoğlu N, Somer A, Badur S, et al. Viral etiology in hospitalized children with acute lower respiratory tract infection. Turk I Pediatr 2011;53:508-16.

13. Semple M, Booth J, Ebrahimi B. Most human metapneumovirus and human respiratory syncytial virus in infant nasal secretions is cell free. I Clin Virol 2007;40:241-4.

14. Singleton RJ, Bulkow LR, Miernyk K, et al. Viral Respiratory Infections in Hospitalized and Community Control Children in Alaska. I Med Virol 2010;82:1282-90.

15. Bicer S, Giray T, Çöl D, et al. Virological and clinical characterizations of respiratory infections in hospitalized children. Ital / Pediatr 2013;27:39-22.

16. Pierangeli A, Gentile M, Di Marco P, et al. Detection and typing by molecular techniques of respiratory viruses in children hospitalized for acute respiratory infection in Rome, Italy. I Med Virol 2007;79:463-8.

17. Azkur D, Özaydın E, Dibek-Mısırlıoğlu E, et al. Viral etiology in infants hospitalized for acute bronchiolitis. Turk I Pediatr 2014;56:592-6. 
18. Pourakbari B, Mahmoudi S, Movahedi Z, et al. Viral etiology of acute lower respiratory tract infections in hospitalized young children in a children's referral hospital in Iran. Turk I Pediatr 2014;56:354-9.

19. Cooper RI, Hallett R, Tullo AB, Klapper PE. The epidemiology of adenovirus infections in Greater Manchester, UK 1982-96. Epidemiol Infect 2000;125:333-45.

20. Prill MM, Iwane MK, Edwards KM, et al. New Vaccine Surveillance Network. Human coronavirus in young children hospitalized for acute respiratory illness and asymptomatic controls. Pediatr Infect Dis ) 2012;31:235-40.

21. Lau SK, Woo PC, Yip CC, et al. Coronavirus HKU1 and other coronavirus infections in Hong Kong. I Clin Microbiol 2006:44:2063-71.

22. Karadag-Oncel E, Ciblak MA, Ozsurekci Y, Badur S, Ceyhan M. Viral etiology of influenza-like illnesses during the influenza season between December 2011 and April 2012. J Med Virol 2014;86:865-71.

23. Ghietto LM, Cámara A, Zhou Y, et al. High prevalence of human bocavirus 1 in infants with lower acute respiratory tract disease in Argentina, 2007-2009. Braz I Infect Dis 2012;16:38-44.

24. Midilli K, Yılmaz G, Türkoğlu $S$, et al. Detection of human bocavirus DNA by polymerase chain reaction in children and adults with acute respiratory tract infections. Mikrobiyol Bul 2010;44:405-13.

25. Uyar M, Kuyucu N, Tezcan S, Aslan G, Tasdelen B. Determination of the frequency of human bocavirus and other respiratory viruses among 0-2 years age group children diagnosed as acute bronchiolitis. Mikrobiyol Bul 2014;48:242-58.

26. Allander T, Jartti T, Gupta $S$, et al. Human bocavirus and acute wheezing in children. Clin Infect Dis 2007;44:904-10.

27. Schenk T, Huck B, Forster I, Berner R, Neumann-Haefelin D, Falcone $V$. Human bocavirus DNA detected by quantitative realtime PCR in two children hospitalized for lower respiratory tract infection. Eur J Clin Microbiol Infect Dis 2007;26:147-9.

28. Fitzgerald DA. Viral bronchiolitis for the clinician. I Paediatr Child Health 2011;47:160-6.

29. Debiaggi $M$, Canducci F, Ceresola ER, Clementi $M$. The role of infections and coinfections with newly identified and emerging respiratory viruses in children. Virol ) 2012;9:247.
30. Freymuth $F$, Vabret $A$, Cuvillon-Nimal $D$, et al. Comparison of multiplex PCR assays and conventional techniques for the diagnostic of respiratory virus infections in children admitted to hospital with an acute respiratory illness. I Med Virol 2006,78:1498-1504

31. Pratheepamornkull T, Ratanakorn W, Samransamruajkit R, Poovorawan Y. Causative agents of severe community acquired viral pneumonia among children in eastern Thailand. Southeast Asian I Trop Med Public Health 2015;46:650-6.

32. Beka $\mathrm{H}$, Kilic $\mathrm{A}$, Unuvar $\mathrm{E}$, et al. Frequency of common viruses in etiology of acute respiratory tract infections. Indian J Pediatr 2013;80:91-6.

33. Lambert SB, Allen KM, Druce JD, et al. Community epidemiology of human metapneumovirus, human coronavirus NL63, and other respiratory viruses in healthy preschool-aged children using parent collected specimens. Pediatrics 2007;120:929-37.

34. Kusel MM, de Klerk NH, Holt PG, Kebadze T, Johnston SL, Sly PD. Role of rhinovirus in acute upper and lower respiratory tract illness in the first year of life: a cohort study. Pediatr Infect Dis ) 2006;25:680-6

35. Juven T, Mertsola J, Waris $M$, et al. Etiology of communityacquired pneumonia in 254 hospitalized children. Pediatr Infect Dis | 2000;19:293-8.

36. Xie $Z D, X i a o ~ Y$, Liu $C Y$, et al. Three years surveillance of viral etiology of acute lower respiratory tract infection in children from 2007 to 2010. Zhonghua Er Ke Za Zhi 2011;49:745-9.

37. Zeng SZ, Xiao NG, Xie ZP, et al. Prevalence of human rhinovirus in children admitted to hospital with acute lower respiratory tract infections in Changsha, China. I Med Virol 2014;86:1983-9.

38. Guittet V, Brouard I, Vabret A, et al. Rhinovirus and acute respiratory infections in hospitalized children. Retrospective study 1998-2000. Arch Pediatr 2003;10:417-23.

39. Linder JE, Kraft DC, Mohamed Y, et al. Human rhinovirus C: Age, season, and lower respiratory illness over the past 3 decades. I Allergy Clin Immunol 2013;131:69-77.

40. Frobert E, Escuret $V$, Javouhey E, et al. Respiratory viruses in children admitted to hospital intensive care units: evaluating the CLART ${ }^{\circledR}$ Pneumovir DNA array. I Med Virol 2011;83:150-5.

41. Wang W, Cavailler P, Ren $P$, et al. Molecular monitoring of causative viruses in child acute respiratory infection in endemoepidemic situations in Shanghai. / Clin Virol 2010;49:211-8. 